\title{
Sintesis Katalis Ni/ZSM-5 untuk Pirolisis Cangkang Sawit Menjadi Bio-Oil
}

\author{
Fajril Akbar, Sunarno \\ Jurusan Teknik Kimia Universitas Riau \\ Kampus Binawidya Jl.Subrantas Km 12,5 Simpang Baru Pekanbaru 28293 \\ *E-mail: narnounri@yahoo.com
}

\begin{abstract}
Increasing of the palm plantation every years can be increase the Crude Palm Oil (CPO) product, effecting the increase of the palm solid waste. One of the solid waste is palm kernel shell which used as energy source for boiler that produce palm ash wich as substant for the synthesis of ZSM-5catalyst (ratio $\mathrm{Si} / \mathrm{Al}=30$ ). The synthesis of $\mathrm{Ni} / \mathrm{ZSM}-5$ by impregnation method at temperature $90^{\circ} \mathrm{C}$, for 6 hours, then calcined by the themperature various of $400^{\circ} \mathrm{C}, 500^{\circ} \mathrm{C}$, and $600^{\circ} \mathrm{C}$ during 4 hours with nitrogen gas is flow, and followed by oxidation with oxygen gas and reduction with hydrogen gas flow for 2 hours at themperature $400^{\circ} \mathrm{C}$ have been conducted. The resulting Ni/ZSM-5 was analyzed by BET method and applied for pyrolysis proccess of the palm kernel shell to produce bio oil. The bio oil product was charactrized for dencity, viscocity and flash point. The result show that maximum surface area of catalyst for calcination obtained at $500^{\circ} \mathrm{C}$ is $67,874 \mathrm{~m}^{2} / \mathrm{g}$, and study of pyrolysis proccess from $1 \%$ mass of palm kernel shell produce of $43 \%$ bio oil yield. The characterization result of bio-oil obtained that density is $0.954 \mathrm{gr} / \mathrm{ml}$, viscosity is $12.65 \mathrm{cp}$, and flash point is $62^{\circ} \mathrm{C}$.
\end{abstract}

Keywords : BET, Bio-Oil, Ni/ZSM-5, Pyrolysis, Solid Waste

\section{I.Pendahuluan.}

Saat ini industri sawit merupakan salah satu komoditas yang memegang peranan penting dalam perekonomian Indonesia. Hal ini dapat dilihat dari luas perkebunan sawit yang meningkat tiap tahunnya, yaitu dari 7,0 juta hektar pada tahun 2008 menjadi 7,3 juta hektar pada tahun 2009. Sedangkan produksi minyak sawit Crude Palm Oil (CPO) terus mengalami peningkatan dari 19,2 juta ton pada tahun 2008 meningkat menjadi 19,4 juta ton pada tahun 2009 (ICN, 2009).

Dengan semakin meningkatnya produksi CPO maka akan mengakibatkan peningkatan jumlah limbah sawit. Untuk itu diperlukan suatu cara agar limbah sawit dapat dimanfaatkan sehingga limbah sawit dapat ditanggulangi. Sawit mengandung lebih kurang 67\% brondolan, 21,5\% tandan kosong, 11,1\% blowdown dan $0,4 \%$ penguapan pertandan buah segar. Tiap brondolan diperoleh CPO (Crude Palm Oil) kasar 43,5\% dan biji serta ampas 23,5\%. Didalam biji mengandung biji 10,4\%, cangkang sekitar 5,4\% dan kernel 5\% (Naibaho, 1996).

Limbah padat berupa cangkang dan sabut digunakan sebagai bahan bakar ketel (boiler) untuk menghasilkan energi mekanik dan panas. Masalah yang kemudian timbul adalah sisa dari pembakaran pada ketel (boiler) berupa abu sawit dengan jumlah yang terus meningkat sepanjang tahun tahunnya yang sampai sekarang masih belum termanfaatkan.

Abu sawit umumnya dibuang di landfill atau ditumpuk begitu saja di dalam area industri. Penumpukan abu sawit dapat menimbulkan masalah lingkungan. Karena abu sawit ini mengandung banyak silika maka dapat dikonversi menjadi silika terspresipitasi (Saputra, 2006). Abu sawit asal Propinsi Riau berupa sabut dan cangkang berkadar silika berturut-turut 61,3 dan $76,2 \%$ berat (Zahrina, 2003). Sehingga penggunaan abu sawit dapat digunakan dalam pembuatan katalis ZSM-5. Katalis ZSM-5 merupakan salah satu zeolit sintesis yang banyak digunakan di industri terutama untuk reaksi perengkahan.

Siswodiharjo (2006) telah melakukan penelitian reaksi hidrorengkah parrafin menggunakan katalis $\mathrm{Ni} /$ Zeolit, Mo/Zeolit dan NiMo/Zeolit. Hasil penelitian menunjukkan bahwa katalis $\mathrm{Ni} /$ Zeolit memiliki efektivitas katalis yang paling baik. Katalis Zeolit akan diganti dengan ZSM-5 karena ZSM-5 memiliki aktivitas dan selektivitas serta stabilitas termal yang tinggi. ZSM5 juga menyediakan permukaan yang luas untuk menebarkan komponen aktif berupa logam.

Untuk memperoleh katalis ZSM-5 yang baik, dibuat suatu sistem logam pengemban yaitu dengan cara menempelkan komponen aktif logam Ni. Keuntungan yang diperoleh adalah komponen aktif logam dapat didistribusikan secara merata ke seluruh pori-pori pengemban sehingga luas permukaan katalis menjadi besar. Katalis Ni/ZSM-5 ini akan diuji kinerjanya dalam proses pirolisis bio-oil.

Bio-oil ini merupakan salah satu energi alternatif pengganti bahan bakar dari minyak bumi yang mengalami penurunan produksi tiap tahunnya. Bio-oil sebagai pengganti bahan bakar minyak bumi memiliki beberapa keuntungan yaitu bio-oil sangat ramah lingkungan karena dapat mendaur ulang limbah, mengurangi penimbunan, mencegah pencemaran tanah dan air tanah, tidak menghasilkan emisi SOx dan ketika dibakar emisi NOx yang dihasilkan hanya sekitar 15\%. 
Karena bio-oil memiliki kandungan nitrogen dan sulfur yang sangat sedikit.

Bio-oil adalah cairan yang dapat larut dalam air, bahan bakar yang dapat dioksigenasi, mengandung karbon, hidrogen dan oksigen.

Anugra (2011) telah melakukan penelitian pirolisis cangkang sawit menjadi bio-oil didapatkan rasio katalis

Sintesis ZSM-5 mengacu pada prosedur yang telah dilakukan oleh Misdian (2009) dengan kondisi suhu 175 ${ }^{\circ} \mathrm{C}, \mathrm{Si} / \mathrm{Al} 30$ selama 18 jam. Terlebih dahulu akan
$1 \%$ wt $\mathrm{Ni} / \mathrm{NZA}$ dan suhu pirolisis $320^{\circ} \mathrm{C}$ dan pada kecepatan pengadukan $300 \mathrm{rpm}$. Tujuan dari penelitian ini adalah untuk menentukan pengaruh variasi suhu kalsinasi terhadap luas permukaan katalis.

\section{Metodologi.}

dilakukan pembuatan silika terpresipitasi dan natrium aluminat.



Gambar 1. Sintesis Katalis Ni/ZSM-5

Sampel ZSM-5 direfluks dengan larutan $\mathrm{Ni}\left(\mathrm{NO}_{3}\right)_{2} \cdot 6 \mathrm{H}_{2} \mathrm{O}$ sebanyak $500 \mathrm{ml}$ pada suhu $90{ }^{\circ} \mathrm{C}$ selama 6 jam, Kemudian disaring dan dicuci. Sampel ini dikeringkan dalam oven pada suhu $105{ }^{\circ} \mathrm{C}$ selama 3 jam sehingga didapat sampel Ni/ZSM-5. Pengembanan logam sebesar $3 \% \mathrm{~b} / \mathrm{b}$ terhadap sampel ZSM-5. dikalsinasi pada variasi suhu $400,500{ }^{\circ} \mathrm{C}$ dengan waktu 4 jam sambil dialirkan gas nitrogen sebesar \pm 400 $\mathrm{ml} /$ menit, dilanjutkan dengan oksidasi pada suhu $400{ }^{\circ} \mathrm{C}$ menggunakan gas oksigen sebesar $\pm 400 \mathrm{ml} / \mathrm{menit}$ selama 2 jam dan reduksi pada suhu $400{ }^{\circ} \mathrm{C}$ menggunakan gas hidrogen sebesar $\pm 400 \mathrm{ml} / \mathrm{menit}$ selama 2 jam.
Untuk menguji aktivitas kinerja Ni/ZSM-5 diuji dengan melakukan pirolisis cangkang sawit mengacu pada penelitian yang telah dilakukan oleh Anugra (2010). Cangkang sawit yang telah dihancurkan ditimbang sebanyak 50 gram dengan ukuran $-40+60$ mesh beserta $500 \mathrm{ml}$ thermal oil (silinap $280 \mathrm{M}$ ) dimasukkan ke dalam reaktor dan ditambahkan $1 \%$-wt Ni/ZSM-5 dari berat cangkang sawit kemudian dilakukan pirolisis pada temperatur $320^{\circ} \mathrm{C}$ dan pada kecepatan pengadukan $300 \mathrm{rpm}$ hingga waktu tertentu. Gas Nitrogen dialirkan ke dalam reaktor dengan laju alir $1,3 \mathrm{~mL} /$ detik. Diulangi dengan variasi suhu kalsinasi $\mathrm{Ni} / \mathrm{ZSM}-5$ lainnya (Ni/ZSM-5 dengan suhu kalsinasi yaitu $\left.400,500{ }^{\circ} \mathrm{C}\right)$. 


\section{Hasil dan Pembahasan.}

\section{a. Analisis Data Suhu Kalsinasi}

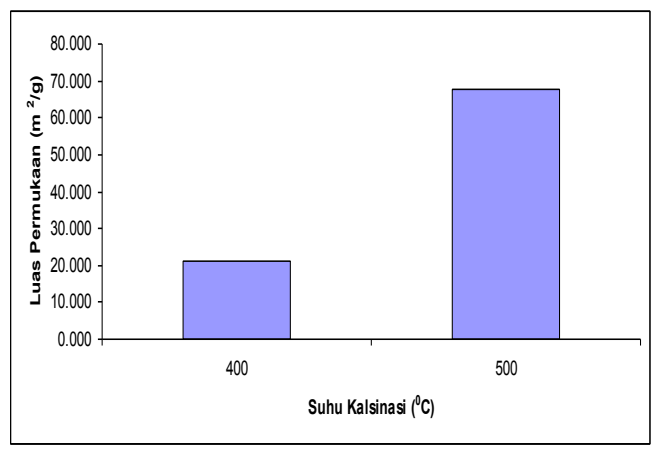

Gambar 2. Hubungan Suhu Kalsinasi Terhadap Luas Permukaan Katalis

Dari Gambar 4.1 diketahui bahwa pada suhu kalsinasi $400^{\circ} \mathrm{C}$ luas permukaan katalis $21,300 \mathrm{~m}^{2} / \mathrm{g}$, suhu kalsinasi $500^{\circ} \mathrm{C}$ dihasilkan luas permukaan 67,874 $\mathrm{m}^{2} / \mathrm{g}$ dan pada suhu kalsinasi $600^{\circ} \mathrm{C}$ dihasilkan luas permukaan 22,959 $\mathrm{m}^{2} / \mathrm{g}$. Dari hasil yang diperoleh diketahui bahwa suhu kalsinasi mempengaruhi luas permukaan katalis Ni/ZSM-5.

Suhu kalsinasi $400^{\circ} \mathrm{C}$ luas permukaan katalis yang diperoleh kecil hal ini disebabkan fasa aktif yang diembankan belum terbentuk secara sempurna. Pendapat ini sesuai dengan penelitian Elmasry [1994] yang menyatakan bahwa fasa aktif terbentuk pada suhu diatas $623 \mathrm{~K}$ atau $350^{\circ} \mathrm{C}$. Ini berarti bahwa perlu suhu yang lebih tinggi agar reaksi kalsinasi dapat berjalan sempurna dan fasa aktif dapat terbentuk.

Tetapi pada suhu $500^{\circ} \mathrm{C}$ terjadi peningkatan luas permukaan katalis Ni/ZSM-5. Pada tahap pengeringan setelah impregnasi, garam prekursor $\mathrm{Ni}\left(\mathrm{NO}_{3}\right)_{2} \cdot 6 \mathrm{H}_{2} \mathrm{O}$ akan berubah menjadi $\mathrm{Ni}_{3}\left(\mathrm{NO}_{3}\right)_{2}(\mathrm{OH})_{4}$ [Sietsma., 2008]. Tahap Kalsinasi terjadi reaksi: $2 \mathrm{H}_{2} \mathrm{O}_{(\mathrm{g})}$

$\mathrm{Ni}_{3}\left(\mathrm{NO}_{3}\right)_{2}(\mathrm{OH})_{4(\mathrm{~s})} \rightarrow 3 \mathrm{NiO}_{(\mathrm{s})}+2 \mathrm{NO}_{2(\mathrm{~g})}+1 / 2 \mathrm{O}_{2(\mathrm{~g})}+$
Reaksi ini menunjukkan bahwa fasa oksida akan terbentuk pada tahap kalsinasi dan gas seperi $\mathrm{NO}_{2}, \mathrm{O}_{2}$, $\mathrm{H}_{2} \mathrm{O}$ akan hilang seiring dengan meningkatnya suhu kalsinasi. Gas-gas seperti $\mathrm{NO}_{2}, \mathrm{O}_{2}, \mathrm{H}_{2} \mathrm{O}$ merupakan pengotor yang jika terdapat pada katalis akan membuat pori-pori katalis dipenuhi pengotor sehingga luas permukaan katalis menjadi kecil. Jika pengotor-pengotor ini hilang secara sempurna maka luas permukaan katalis akan meningkat karena pori-pori katalis lebih terbuka.

Selanjutnya tahap oksidasi yang bertujuan untuk mengubah sisa-sisa logam atau nonlogam yang mengganggu stabilitas dan aktivitas katalis logam pengemban supaya menjadi senyawa-senyawa oksidanya sehingga mudah untuk meninggalkan permukaan pengemban. Kemudian fasa oksida ini akan direduksi menjadi logam Ni yang diinginkan.

$$
3 \mathrm{NiO}_{(\mathrm{s})}+\mathrm{H}_{2} \rightarrow 3 \mathrm{Ni}_{(\mathrm{g})}+\mathrm{O}_{2(\mathrm{~g})}+\mathrm{H}_{2} \mathrm{O}_{(\mathrm{g})}
$$

Hal ini menunjukkan bahwa suhu kalsinasi yang lebih tinggi dari $400^{\circ} \mathrm{C}$ menghasilkan luas permukaan yang luas seperti pada suhu $500^{\circ} \mathrm{C}$.

b. Analisis Data Luas Permukaan Katalis dan Yield Bio-Oil

Tabel 4.1 Hasil Perolehan Yield Bio-Oil

\begin{tabular}{ccc}
\hline $\begin{array}{c}\text { Suhu } \\
\text { Kalsinasi } \\
\left({ }^{\mathbf{0}} \mathbf{C}\right)\end{array}$ & $\begin{array}{c}\text { Luas Permukaan } \\
\text { Ni/ZSM-5 } \\
\left(\mathbf{m}^{\mathbf{2}} / \mathbf{g}\right)\end{array}$ & $\begin{array}{c}\text { Yield } \\
\text { Bio-Oil } \\
(\%)\end{array}$ \\
\hline 400 & 21.300 & 32 \\
500 & 67.874 & 40 \\
\hline
\end{tabular}

Tabel 4.1 menunjukkan data hasil perolehan yield bio oil pada berbagai variasi suhu kalsinasi pada katalis Ni/ZSM5. Persentase yield bio oil dengan katalis Ni/ZSM-5 dengan berbagai suhu kalsinasi $\left(400^{\circ} \mathrm{C}, 500^{\circ} \mathrm{C}\right)$ dipirolisis pada temperatur $320^{\circ} \mathrm{C}$ berturut-turut adalah $31 \%, 42 \%$.

Luas permukaan katalis yang mempengaruhi yield bio oil yang dihasilkan. Hal ini ditunjukkan dengan hasil luas permukaan $67,874 \mathrm{~m}^{2} / \mathrm{g}$ menghasilkan yield bio oil yang besar yaitu $42 \%$. Luas permukaan katalis akan mempengaruhi aktivitas katalis, semakin luas permukaan suatu katalis maka fasa aktif yang tersebar semakin banyak sehingga akan meningkatkan aktivitas [Putera,2008]. 


\section{c. Karakterisasi Bio-Oil}

Tabel 4.2 Perbandingan Karakteristik Bio Oil yang Dihasilkan dengan Standar Referensi.

\begin{tabular}{cccc}
\hline No & Parameter & $\begin{array}{c}\text { Standar Bio Oil } \\
\text { [Smallwood, 2008] }\end{array}$ & $\begin{array}{c}\text { Bio Oil } \\
\text { Ni/ZSM-5 }\end{array}$ \\
\hline 1 & Massa Jenis, gr/ml & $0,94-1,2$ & 0,954 \\
2 & Viskositas, cp & $10-150$ & 12,65 \\
3 & Titik Nyala, ${ }^{0} \mathrm{C}$ & $48-55$ & 62 \\
\hline
\end{tabular}

\section{Kesimpulan.}

Berdasarkan hasil penelitian yang dilakukan dan pembahasannya, maka dapat disimpulkan bahwa Pada sintesis katalis Ni/ZSM-5 penelitian ini, suhu kalsinasi mempengaruhi luas permukaan katalis. Luas permukaan yang paling besar dihasilkan pada suhu kalsinasi $500^{\circ} \mathrm{C}$ yaitu $67,874 \mathrm{~m}^{2} / \mathrm{g}$. Hasil pengujian aktivitas katalis Ni/ZSM-5 pada proses pirolisis cangkang sawit menjadi bio-oil menunjukkan luas permukaan katalis berbanding lurus terhadap yield bio-oil yang dihasilkan. Hasil karakteristik bio-oil pada proses pirolisis cangkang sawit dengan menggunakan katalis Ni/ZSM-5 diketahui densitas bio-oil : 0,954 gr/ml, viskositas : 13,196 cSt dan titik nyala $62^{\circ} \mathrm{C}$.

\section{Ucapan Terimakasih}

Ucapan terimakasih kepada Elfrida dan pihak-pihak yang membantu terlaksananya penelitian.

\section{Daftar Pustaka.}

Anugra, R. D., 2011, Efek Kandungan Logam Ni/NZA Pada Proses Pencairan Langsung Biomassa Menjadi Bio Oil, Laporan Penelitian, Jurusan Teknik Kimia Fakultas Teknik, Pekanbaru.

Elmasry, M. A. A., Gaber, A., Khater, M. H., 1998, Thermal Decomposition of Ni(ii) and Fe(iii) Nitrates and Their Mixture, Journal of Thermal Analysis, vol 52, no 489-495.

Indonesian Commercial Newsletter, 2009, Industri Palm Oil di Indonesia November 2009, http://www.datacon.co.id/CPO12009Sawit.html, 1 April 2011.

Misdian, D., 2009, Pembuatan CoMo/ZSM-5 dari Abu Sawit Sebagai Katalis pada Pengolahan Biomassa Menjadi Bahan Bakar Cair, Laporan Penelitian, Jurusan Teknik Kimia Fakultas Teknik Universitas Riau, Pekanbaru.

Naibaho, Ponten M., 1996. Teknologi Pengolahan Kelapa Sawit, Pusat Penelitian Kelapa Sawit, Medan.
Putera, D. D., 2008, Sintesis Fotokatalisis $\mathrm{CuO} / \mathrm{ZnO}$ untuk Konversi Metanol Menjadi Hidrogen, Skripsi, Program Studi Kimia Fakultas Matematika dan Ilmu Pengetahuan Alam Institut Teknologi Bandung.

Saputra, E., Utama P. S., dan Aman, 2006, Pembuatan Industrial Grade Silica Dari Limbah Padat Abu Sabut Sawit dengan Proses Ekstraksi dan SolGel, Kumpulan Hasil Penelitian Unggulan Universitas Riau, Lembaga Penelitian UR, Hal 199-201.

Sietsma, Jelle R, A., Friedrich, H., Broersma, A., Versluijis-Helder, M., Dillen, A. J. V., Jongh, P, E., Jong K, P., 2008, How Nitric oxide affects the decomposition of supported nickel nitrate to arrive at highly dispersed catalyst, Elsevier, Netherlands, 227-235.

Siswodiharjo, 2006, Reaksi Hidrorengkah Katalis Ni/Zeolit, Mo/Zeolit, Ni-Mo/Zeolit Terhadap Parafin, Abstrak, FMIPA UNS, Surakarta.

Zahrina, I. dan Rina, D.S., 2003, Studi Pemanfaatan Abu Sawit Sebagai Sumber Silika Pada Konversi Zeolit Alam Menjadi ZSM - 5, Laporan Penelitian, Lembaga Penelitian UR, Pekanbaru. 